\title{
Factors Affecting Quality of Emergency Service in Iran's Military Hospitals: A Qualitative Study
}

Rouhollah Zaboli ${ }^{1}$, Mohamad Shokri², Maryam Seyed Javadi ${ }^{3}$, Ehsan Teymourzadeh ${ }^{4}$, Ahmad Ameryoun $^{5}$

${ }^{1}$ Ph.D. of Health Services Administration, Assistant Professor, Health Management Research Center, Baqiyatallah University of Medical Sciences, Tehran, Iran

${ }^{2}$ Ph.D. Candidate of Health Services Administration, Department of Health Services Administration, Faculty of Health, Baqiyatallah University of Medical Sciences, Tehran, Iran

${ }^{3}$ Ph.D. Candidate of Health Services Administration, Department of Health Services Administration, School of Health Management and Information Sciences, Iran University of Medical Sciences, Tehran, Iran

${ }^{4}$ Ph.D. of Health Services Administration, Assistant Professor, Health Management Research Center, Baqiyatallah University of Medical Sciences, Tehran, Iran

${ }^{5} \mathrm{Ph} . \mathrm{D}$. of Health Services Administration, Associate Professor, Health Management Research Center, Baqiyatallah University of Medical Sciences, Tehran, Iran

Type of article: Original

\begin{abstract}
Introduction: Quality is a key factor for the success of any organization. Moreover, accessing quality in the emergency department is highly significant due to the sensitive and complex role of this department in hospitals as well as the healthcare and medical treatment system. This study aimed to identify, from the perspective of medical experts and nurses serving in the military health and medical treatment system, the factors that affect the quality of emergency service provided in selected military hospitals in Iran.

Methods: This qualitative research was performed in Valiaser Hospital of Tehran (Iran) in 2015, using the framework analysis method. The purposive sampling technique was used for data collection. A total of 14 participants included two emergency medicine specialists, four general physicians, two senior nurses (holding M.Sc. degrees), and six nurses (holding B.Sc. degree). Data were collected through semistructured interviews. Sampling continued until data saturation occurred. The Atlas/Ti software was employed for data analysis.

Results: Four basic themes emerged as the effective factors on the quality of emergency services, namely, structural themes, process/performance themes, outcome themes, and environmental/contextual themes. Moreover, through a framework analysis, 47 subthemes were specified and summarized as indicators of the different aspects of the main themes.

Conclusion: The factors affecting the quality of emergency services in Iran's selected military hospitals are especially complicated due to the diversity of the missions involved; thus, different factors can influence this quality. Therefore, an effort should be made to tackle the existing obstacles, facilitate the identification of these effective factors, and promotion of the quality of healthcare services.

Keywords: Quality, Military Hospital, Emergency Department
\end{abstract}

\section{Introduction}

Quality is a key factor for the success of any organization (1). Increasing trends have been recently observed among the experts and management of health and medical treatment services for quality assessment of such services (2). One key principle in emergency services standards is that the healthcare providers should monitor the quality and safety of such services (3). Numerous definitions have been set forth for quality. The Institute of Medicine (IOM) defines quality as, "a degree of healthcare services provided for individuals and society which is in conformity with the current expert practices and knowledge and leads to increased likelihood of obtaining favorable results" (4). Quality improvement is a major part of planning and service provision in general wards (5) and, due to the changes

\section{Corresponding author:}

Associate Professor Dr. Ahmad Ameryoun, Health Management Research Center, Baqiyatallah University of Medical Science, Tehran, Iran. Tel: +98.2182483510,Email: ad_amer_heli@yahoo.com

Received: February 01, 2016, Accepted: May 18, 2016, Published: September 2016

iThenticate screening: May 15, 2016, English editing: July 12, 2016, Quality control: Augyst 02, 2016

(C) 2016 The Authors. This is an open access article under the terms of the Creative Commons Attribution-NonCommercialNoDerivs License, which permits use and distribution in any medium, provided the original work is properly cited, the use is non-commercial and no modifications or adaptations are made. 
introduced in the healthcare systems, is a main challenge in hospitals (6). In the past 20 years, emergency medical services have been on the rise (7). Annually, more than 119 million and 112 million emergency room visits are conducted in the United States and Canada, respectively. From 1996 to 2006, emergency room visits in the United States have shown a 32\% (approximately) increase. A similar trend exists in emergency departments in Canada, Australia, and certain parts of Europe [8]. About $25 \%$ of the patients visiting hospitals are emergency patients. Of these, $40 \%$ are hospitalized after the initial admission (9). As the main gate and source of outpatients in a hospital, the emergency department experiences an annual increase in the number of visits; therefore, it is always crowded, a condition that causes service quality deterioration (10). On the other hand, the emergency department plays a particularly sensitive role as a stressful working environment (11) due to the fact that its staff has to perform quick, high quality, and effective processes (12). The organizational structure of the emergency department is vastly different from that of other hospital wards due to the relief and revival services provided in this department (13). For this reason, increasing efforts are being made toward making quality services available in emergency departments (14). Improving quality has been considered as an important problem in the past decades, and countries have tried to provide high-quality and safe healthcare services (8). There are several reasons for this, including increased complexity of healthcare systems and organizations, concentration on effectiveness and efficiency, increased pressure to reduce costs and strengthening the position of the customer (15), competition in the healthcare market, and increased patient safety knowledge (16). Quality healthcare for patients is addressed as a challenge. Liu et al. used the structure-process-outcome framework described by Donabedian, which is a three-part approach. In this method, structure affects the process and, ultimately, will affect the outcome. Therefore, the factors that might reduce quality in the emergency department were conceptualized and the problems regarding the relationship between these themes were resolved within the defined framework. To develop the framework, other quality fields, including that of Insinuation of Medicine (IOM), were used in addition to Donabedian's model. Moreover, those aspects with clinical credibility based on researchers' experience were implemented. The framework included the organization (e.g., physical environments, service provider's skills/performance, distractions, and documenting treatment measures), process (including patient observation, welfare, diagnosis, and treatment), and outcome (e.g., adopting IOM fundamentals, namely, accepting responsibility, service provider's satisfaction, efficiency, and accessibility). Ultimately, this framework was introduced as a practical framework for researchers. It is emphasized that this framework is not complete due to having been designed by a small group of experts, and that further research is required in this regard (17). However, many hospital managers do use the thematic Donabedian's structure-process-outcome framework (18). Healthcare quality is a multidimensional subject (19). A 2012 study by Bennet showed three conditions for healthcare services quality: 1) the best consequence at the least risk; 2) timely care in the best situation; and 3) correct, proper, and immediate care provision. The number of global healthcare indicators is on the rise. Ten such indicators refer to nursing services in the emergency rooms (20). The World Health Organization (WHO) suggests that healthcare systems must seek quality in the following six regards: efficiency, effectiveness, accessibility, acceptability/patient-orientation, justice, and safety (21). A 2011 study by Esmaili showed that clinical decision-making was an important process used by nurses to provide care services for patients. In line with this, the authors refer to five effective factors that can affect the decision-making process (22). A 2013 study by Rahimi showed that the concentration on patients' needs and expectations was necessary to achieving a suitable quality model. They then enumerated nine effective factors that affected quality and were related to the physical environment (12). A 2012 study by Gholipouri showed five factors that affected patient satisfaction in the emergency room. These can be considered as the following subthemes of structure, process, and outcome (23). Efficient information management is essential in providing timely and high-quality healthcare (24). To achieve such efficiency, quality indexes are required as instruments for improving healthcare (2). There is no pattern to assess the quality of emergency services in military hospitals in Iran. Iran's military hospitals are evaluated on the basis of national accreditation standards, and specific conditions in military hospitals here will be ignored. On the other hand, the military hospital plays an important role in the delivery of services and events that are in critical condition and a disaster. The main purpose of this research is to carry out a focused qualitative study to identify the factors affecting the quality of emergency services in the selected military hospitals in Iran. As such, the study was conducted for describing the real-life experiences of Iran's military healthcare and treatment experts.

\section{Material and Methods}

This is a qualitative study using the framework analysis method, which is an approach used for analyzing qualitative data in developmental policy-making studies and is increasingly used in healthcare services research (25). The study was performed in Valiaser Hospital of Tehran (Iran) in 2015. The participants comprised 14 military medical experts in Iran in 2015. The entry criteria included at least 5 years of experience in a military hospital emergency department, being an expert in the field of quality management as well as emergency medicine, and having 
medical/nursing academic background. The semistructured interview method was employed to collect the required data. This is an approach for deep exploration of the participants' references (26), and the semistructured guide was used as an instrument for conducting the interviews. First, two pilot interviews were conducted. The interviews were recorded and transcribed; ultimately, the finalized interview guide was prepared. Then, based on the targeted sampling method and the entry criteria applied for the study, the interviews were held. The interviews were all recorded and transcribed. The framework analysis method was used for data analysis. This approach included five flexible and interrelated stages. Upon preparing a written copy of the interviews, the data were analyzed using Atlas/ti, qualitative research software. In the first stage (familiarization), a text copy of the interviews was given as input to the software. For better data familiarization, the interview texts were reviewed, and the main recurring ideas were determined. In the second stage (identifying a thematic framework), the recurring ideas were combined and contrasted to identify the basic themes (themes). In the third stage (indexing), the software was used to ensure the framework was proportional to the data. In the fourth stage (charting), the data were summarized as thematic charts; thus, data interpretation was facilitated. In the fifth stage (mapping and interpretation), the thematic charts resulting from the previous stage were reviewed through comparing them with the initial data, and the main themes and dependent subthemes were compared to see whether any new classifications were required. Different methods were employed to produce exact data examination and data trustworthiness, including the peer debriefing technique. The results were duly presented to the relevant experts. A member check technique was also used and obtained results and data analysis output were duly presented to the participants, and their approval was obtained.

\section{Results}

The 14 participants in this study were interviewed: 13 of the study population were male and one was female; eight of the study population have work experiences of more than 5 years in the emergency department (Table 1). Because the authors' main purpose was conducting an interview to obtain a list of effective factors on quality in accordance with the views expressed by authorities in the field, the final results of the framework analysis are summarized in Table 2. These tables describe the main themes and the dependent subthemes and comprise four main themes and 47 subthemes overall, which indicate the different aspects of the main themes during the framework analysis.

Table 1. Basic particulars of the interviewees in the interview research (14 persons)

\begin{tabular}{|c|c|c|c|c|c|c|c|c|}
\hline \multirow[t]{2}{*}{ Participants } & \multicolumn{2}{|l|}{ Gender } & \multicolumn{4}{|c|}{ Education } & \multicolumn{2}{|c|}{$\begin{array}{l}\text { Experience in } \\
\text { Emergency } \\
\text { Department }\end{array}$} \\
\hline & Female & Male & $\begin{array}{l}\text { B.Sc. in } \\
\text { Nursing }\end{array}$ & $\begin{array}{l}\text { M.Sc. in } \\
\text { Nursing }\end{array}$ & $\begin{array}{l}\text { Doctorate in } \\
\text { General } \\
\text { Medicine }\end{array}$ & $\begin{array}{l}\text { Emergency } \\
\text { Medicine } \\
\text { Specialist }\end{array}$ & $\begin{array}{l}5 \\
\text { Years }\end{array}$ & $\begin{array}{l}\text { More than } \\
5 \text { Years }\end{array}$ \\
\hline P1 & & $*$ & & & & $*$ & & $*$ \\
\hline P1 & & $*$ & & & $*$ & & $*$ & \\
\hline P2 & & $*$ & & & $*$ & & $*$ & \\
\hline P3 & & $*$ & & & & & & \\
\hline P4 & & $*$ & $*$ & & & & & $*$ \\
\hline P5 & & $*$ & & $*$ & & & $*$ & \\
\hline P6 & & $*$ & & & $*$ & & & $*$ \\
\hline P7 & & $*$ & & & & $*$ & & $*$ \\
\hline P8 & & $*$ & & $*$ & & & & $*$ \\
\hline P9 & & $*$ & & & $*$ & & $*$ & \\
\hline P10 & & $*$ & $*$ & & & & & $*$ \\
\hline P11 & $*$ & & $*$ & & & & & $*$ \\
\hline P12 & & $*$ & & & & & & $*$ \\
\hline P13 & & $*$ & & & & & & $*$ \\
\hline P14 & & $*$ & $*$ & & & & & $*$ \\
\hline Sum & 1 & 13 & 6 & 2 & 4 & 2 & 3 & 11 \\
\hline
\end{tabular}

\subsection{Main Theme 1: Structural Factors}

In the participants' view, structural factors comprising a main theme with 10 subthemes, obtained in the present study, affected the quality in the emergency room. Participants used different phrases for conveying this implication. One participant stated, "The human resources structure is not proportional to the activities of a medical center, particularly an emergency medical facility" (P3). Another participant said, "Duties must be specified and staff 
training must be in accordance with these duties" (P8). The physical environment was important in the eyes of the participants. According to one participant, "The physical environment is $100 \%$ effective. The environment must be fully expressive, i.e., the patient must not feel bewildered upon entering the emergency room, and must not need to ask such questions as 'where is the doctor's room?' or 'what bed should be used?" (P1). From the participants' perspective, experience played a great role. One participant said, "The new personnel who have recently graduated and qualified are not experienced enough. They are assigned to the emergency department, and they are unable to cope with the crowded and busy environment of this department" (P1).

Table 2. Main themes and the associated subthemes

\begin{tabular}{|c|c|}
\hline Main Themes & Main Subthemes \\
\hline Structural Factors & $\begin{array}{ll}- & \text { Specific job description } \\
\text { - } & \text { Organizational human resource structure } \\
\text { - } & \text { Physical space } \\
\text { - } & \text { Employees' experience } \\
\text { - } & \text { Employees' skills } \\
\text { - } & \text { Applied training } \\
\text { - } & \text { Number of beds } \\
\text { - } & \text { Updated standard medical equipment } \\
\text { - } & \text { Documenting treatment measures } \\
\text { - } & \text { Hiring expert employees }\end{array}$ \\
\hline Process/Performance Factors & $\begin{array}{ll}\text { - } & \text { Crowded waiting rooms } \\
\text { - } & \text { Triage } \\
\text { - } & \text { Clinical guide } \\
\text { - } & \text { Hoteling } \\
\text { - } & \text { Coordinated accountable para clinics } \\
\text { - } & \text { Behavior towards patients and relationship between employees and } \\
& \text { patients } \\
- & \text { Presence of specialists }\end{array}$ \\
\hline Consequential Factors & $\begin{array}{ll}\text { - } & \text { Timely disposition of patients } \\
\text { - } & \text { Release upon personal consent } \\
\text { - } & \text { Employees' motivational problems } \\
\text { - } & \text { Timely service provision } \\
\text { - } & \text { Patients' satisfaction } \\
\text { - } & \text { Strategic plan } \\
- & \text { Mortality rate } \\
- & \text { Patient-oriented } \\
- & \text { Successful CPR } \\
- & \text { Efficiency } \\
- & \text { Safety } \\
- & \text { Errors } \\
- & \text { Morbidity } \\
\end{array}$ \\
\hline $\begin{array}{l}\text { Environmental/Background } \\
\text { Factors }\end{array}$ & $\begin{array}{ll}- & \text { supervisory role of superior organizations } \\
\text { - } & \text { cultural problems } \\
\text { - } & \text { special visits and military missions } \\
- & \text { sabbatical year grants } \\
\text { - } & \text { enforcement of productivity promotion regulations } \\
\text { - } & \text { patients' expectations } \\
- & \text { military laws and regulations } \\
- & \text { central military missions } \\
- & \text { employee transfer } \\
- & \text { selecting and absorbing interested employees } \\
- & \text { institutionalizing military medicine approach } \\
- & \text { management and leadership style } \\
- & \text { strict implementation of the adaptation plan } \\
- & \text { economic sanctions } \\
- & \text { facilitating foreign travels and exiting procedure }\end{array}$ \\
\hline
\end{tabular}




\subsection{Main Theme 2: Process/Performance Factors}

The main theme here was accompanied by seven dependent subthemes, and interviewees believed it to be effective in raising the quality in the emergency room. According to one participant, "Moral issues are very important in the emergency section. If patients are handled properly, their restlessness and stress would automatically be reduced" (P7). Another participant stated, "Another index is the presence of the specialist and the 'on-call' doctor, so that they can quickly determine the requirements of each patient and help bring him out of his critical state" (P6). Crowded rooms also were an effective factor. One participant said, "This is not an emergency room, but a bus terminal. The personnel of other hospital wards pass through the emergency room; so do visitors. This adversely affects the quality. When the emergency room is crowded and busy, we sometimes lose our own particular patients" (P1).

\subsection{Main Theme 3: Outcome Factors}

This main theme emerged along with 14 dependent subthemes. The interviewees in this study believed the quality of the emergency services could be affected by examining these factors, including the following: One participant stated, "He decides whether this or that patient should be immediately hospitalized. He decides whether my patients must be discharged or kept in the emergency room for further diagnosis" (P7). With regards to patient-orientation, a participant said, "Some people think you must use strong language in response to aggressive behavior. But, we believe the patient is always right" (P11). The interviewees believed that employees' motivational factors also must be taken into account. As a participant argued, "Personnel motivation can itself be a factor which affects service provision and patient satisfaction. However, personnel motivation is itself one big challenge" (P6). Discharging patients by obtaining their own consent was considered as a consequence of quality services. One interviewee said in this regard, "Discharge through personal consent of the patients can be regarded as a factor for evaluating the quality and an index of emergency services" (P9). Timely services were also considered to be important. According to a participant, "In my opinion, in a high quality emergency room, a patient must receive the most required emergency services in the shortest possible time" (P1).

\subsection{Main Theme 4: Environmental/contextual Factors}

The participants in the study believed that a set of factors could affect the quality of emergency services in military hospitals due to the military nature of such hospitals. These factors were categorized as the environmental/contextual factors. Sixteen subthemes were identified for this main theme. One participant stated, "We have to act according to the management codes and the regulations imposed by our superiors. A number of procedures are issued by the Armed Forces General Headquarters, others by the Command Headquarters, and still others by the Ministry of Health and Medical Education" (P12). Another participant said, "Patients in military hospitals can be different. Patients in need of operations are transferred to certain hospitals, whereas in other hospitals, such a situation does not exist. These patients include criminals or the military personnel suffering from bullet wounds incurred during military operations" (P1). The participants stressed the Productivity Promotion Law was not enforced in military hospitals in Iran. One participant stated, "In university hospitals, this law was enforced a long time ago, 5 or 6 years. This means that a nurse may have merely a 12 -hour off-duty after completing a 24 hour shift during a holiday" (P9). According to one participant, emergency department employees were also sent on military missions, "Due to the different missions assigned to us and the various involvements of the emergency personnel, there are discrepancies in the emergency room services" (P6). The military medicine approach was believed to be highly effective on quality, as one participant said, "For treating injuries caused due to occupational hazards, gunshot wounds, penetrating/non-penetrating trauma, explosions, and mines, we must receive special training. There must be training also for occupational medicine, environmental pollution, drugs, and the threats posed by the personnel themselves. Therefore, the trainings must be proportional to potential occupational injuries, and in case any structural changes are required, the military medicine and military emergency medicine must be defined" (P8).

\section{Discussion}

Military hospitals are responsible for maintaining, restoring, and improving the health of the Armed Forces. A main objective in these hospitals is to provide high-quality services to patients. Civilian hospitals have no such responsibility. As a stressful stage in one's life, serving in the armed forces and military organizations can be accompanied with psychological consequences, thus affecting the person's physical and mental health (41). This is also true about the employees of military hospitals, depending on the type of their service, military rules, and regulations, and the underlying factors referred to by the participants in this study. Civilian hospitals employees are less involved with such problems. Therefore, a management approach in military medical treatment centers must, due to the higher and more complicated expectation levels, also include structural, economic, and political variables 
(42). Unlike civilian hospitals, the main approach in a military hospital is based on military medicine. Military hospitals admit patients who, due to their exceptional professional conditions, are exposed to specific risks and diseases. Increasing trends in combat and terrorist accidents, and the new developments in war strategies, warfare, and the effects thereof, military medicine is also under development. This calls for doctors and nurses to acquire extraordinary knowledge, insight, and skills. Quality assessment methodologies and measures must be developed if the interests of all the customers and stakeholders are to be served. Thus, the proposed framework can be potentially used as a strategy to promote quality in military hospital emergency departments because this strategy is based on the views expressed by a group of health care providers who are responsible for providing the greater part of medical treatment in hospitals; the second reason is that the proposed framework reflects the problems and background requirements in the health system, relief operations, and military treatment. Interested researchers can use the ways presented to them in this study as a basis for their own research in the future. Due to the military nature of this study, there were certain limitations with regards to the following: 1) obtaining authorization to conduct research inside military hospitals; 2) gaining access to the interviewees' information; and 3) obtaining the consent of the participants.

\section{Conclusions}

The factors affecting the quality of emergency services in Iran's military hospitals were the structural factors such as manpower status, so it can be concluded that the quality of services in these hospitals can be increased by using an experienced and expert staff. It is recommended to the accreditation of the military hospital to pay more attention to structural variables.

\section{Acknowledgments:}

This study was a part of Ph.D. dissertation at Baqiyatallah University of Medical Sciences. The researchers express their gratitude to all of the experts at the Valiasr Hospital for their help in conducting this study.

\section{Conflict of Interest:}

There is no conflict of interest to be declared.

\section{Authors' contributions:}

All authors contributed to this project and article equally. All authors read and approved the final manuscript.

\section{References:}

1) Albassam T, Alshawi S. Service Quality Measurement in the Specific Context of Internet-Based SelfService Technologies: A Review. UK Academy for Information Systems Conference Proceedings. 2009; 1.

2) De Vos M, Graafmans W, Keesman E, Westert G, van der Voort PH. Quality measurement at intensive care units: which indicators should we use? J Crit Care. 2007; 22(4): 267-74. doi: 10.1016/j.jcrc.2007.01.002. PMID: 18086396.

3) Rahman NH, Tanaka H, Shin SD, Ng YY, Piyasuwankul T, Lin CH, et al. Emergency medical services key performance measurement in Asian cities. Int J Emerg Med. 2015; 8(1): 12. doi: 10.1186/s12245-0150062-7. PMID: 25932052, PMCID: PMC4412872.

4) El Sayed MJ. Measuring quality in emergency medical services: a review of clinical performance indicators. Emerg med int. 2012; 2012: 161630. doi: 10.1155/2012/161630. PMID: 22046554, PMCID: PMC3196253.

5) O'Reilly P. Involving service users in defining and evaluating the service quality of a disability service. Int J Health Care Qual Assur. 2007; 20(2-3): 116-29. doi: 10.1108/09526860710731816. PMID: 17585611.

6) Botje D, Klazinga NS, Wagner C. To what degree is the governance of Dutch hospitals orientated towards quality in care? Does this really affect performance? Health Policy. 2013; 113(1-2): 134-41. doi: 10.1016/j.healthpol.2013.07.015. PMID: 23953878.

7) Meisel ZF, Shea JA, Peacock NJ, Dickinson ET, Paciotti B, Bhatia R, et al. Optimizing the Patient Handoff Between Emergency Medical Services and the Emergency Department. Ann Emerg Med. 2015; 65(3): 310 7. doi: 10.1016/j.annemergmed.2014.07.003. PMID: 25109535.

8) Makai P, Klazinga N, Wagner C, Boncz I, Gulacsi L. Quality management and patient safety: Survey results from 102 Hungarian hospitals. Health Policy. 2009; 90(2-3): 175-80. doi: 10.1016/j.healthpol.2008.09.009. PMID: 19004518. 
9) Arab M, Movahed KE, Mahmoodi M. Surveing Contributory Factors of Clients'satisfaction in Emergency Unit of Selected Hospitals Affiliated with Tehran and Shahid Beheshti University of Medical Sciences. Hospital. 2015; 14(1): 37-49.

10) Shen $X$, Wang $X$. Improving the health-care delivery process at hospital emergency services by a better use of inpatient bed information. Electronic Commerce Research and Applications. 2015; 14(1): 14-22. doi: 10.1016/j.elerap.2014.10.008.

11) Bragard I, Fleet R, Etienne AM, Archambault P, Légaré F, Chauny JM, et al. Quality of work life of rural emergency department nurses and physicians: a pilot study. BMC Research Notes. 2015; 8(1): 116. doi: 10.1186/s13104-015-1075-2.

12) Rahimi SH, Masoumpour M, Kharazmi E, Kavousi Z. Designing the Quality of Emergency Ward Services in Shirazs Shahid Faghihi Hospital Based on Quality Function Deployment Method (QFD) in 2011-2012. J Hospital. 2013; 12(3): 9-17.

13) Dormann H, Diesch K, Ganslandt T, Hahn EG. Numerical parameters and quality indicators in a medical emergency department. Dtsch Arztebl Int. 2010; 107(15): 261-7. doi: 10.3238/arztebl.2010.0261. PMID: 20458367, PMCID: PMC2864440.

14) Schull MJ, Guttmann A, Leaver CA, Vermeulen M, Hatcher CM, Rowe BH, et al. Prioritizing performance measurement for emergency department care: consensus on evidencebased quality of care indicators. CJEM. 2011; 13(5): 300-9. PMID: 21955411.

15) Van Harten WH, Casparie TF, Fisscher OA. The evaluation of the introduction of a quality management system: a process-oriented case study in a large rehabilitation hospital. Health Policy. 2002; 60(1): 17-37. doi: 10.1016/S0168-8510(01)00187-7. PMID: 11879943.

16) Wardhani V, Utarini A, van Dijk JP, Post D, Groothoff JW. Determinants of quality management systems implementation in hospitals. Health Policy. 2009; 89(3): 239-51. doi: 10.1016/j.healthpol.2008.06.008. PMID: 18752866.

17) Liu SW, Singer SJ, Sun BC, Camargo CA JR. A conceptual model for assessing quality of care for patients boarding in the emergency department: structure-process-outcome. Acad Emerg Med. 2011; 18(4): 430-5. doi: 10.1111/j.1553-2712.2011.01033.x. PMID: 21496148, PMCID: PMC3682926.

18) Kalyan Y, Bansal R, Mathur S, Singh RK. Quality Assessment in Hospital: A Case Study, 2015.

19) Untachai S. Modeling Service Quality in Hospital as a Second Order Factor, Thailand. Procedia-Social and Behavioral Sciences. 2013; 88: 118-33. doi: 10.1016/j.sbspro.2013.08.487.

20) Bennett P. Nursing quality indicators: The next step in enhancing quality in emergency care. Int Emerg Nurs. 2012; 20(3): 179-86. doi: 10.1016/j.ienj.2012.04.001. PMID: 22912990.

21) World Health Organization. Quality of care: a process for making strategic choices in health systems. 2006.

22) Esmaeili VS, Cheraghi M, Masoudi R, Rabiee L. Decision Making in Prehospital Emergency Nurses: A Qualitative Research. 2011; 3(1-2): 19-32.

23) Soleimanpour H, Gholipouri CH, Salarilak SH, Raoufi P, Rajaei Ghafouri R, Pouraghaei M, et al. Assessment of patient satisfaction with emergency department services in Imam Khomeini Hospital, Tabriz, Iran. Urmia Medical J. 2012; 23(1): 22-31.

24) Aronsky D, Jones I, Lanaghan K, Slovis CM. Supporting patient cares in the emergency department with a computerized whiteboard system. J Am Med Inform Assoc. 2008; 15(2): 184-94. doi: 10.1197/jamia.M248. PMID: 18096913, PMCID: PMC2274795.

25) Khajavi A. Contingency model of patient safety for Tehran University of Medical Sciences hospitals. Tehran University of Medical Sciences. 2013.

26) Barratt H, Harrison DA, Fulop NJ, Raine R. Factors that influence the way communities respond to proposals for major changes to local emergency services: a qualitative study. PloS one. 2015; 10(3): 0120766. doi: 10.1371/journal.pone.0120766. PMID: 25807143, PMCID: PMC4373871.

27) Welch SJ, Asplin BR, Stone-Griffith S, Davidson SJ, Augustine J, Schuur J, et al. Emergency department operational metrics, measures and definitions: results of the second performance measures and benchmarking summit. Ann Emerg Med. 2011; 58(1): 33-40. doi: 10.1016/j.annemergmed.2010.08.040. PMID: 21067846.

28) Matthaeus-Kraemer CT, Thomas-Rueddel DO, Schwarzkopf D, Rueddel H, Poidinger B, Reinhart K, et al. Barriers and supportive conditions to improve quality of care for critically ill patients: A team approach to quality improvement. J Critical Care. 2015; 30(4): 685-91. doi: 10.1016/j.jcrc.2015.03.022.

29) Madsen M, Kiuru S, Castrèn M, Kurland L. The level of evidence for emergency department performance indicators: systematic review. Eur J Emerg Med. 2015; 22(5): 298-305. doi: 10.1097/MEJ.0000000000000279. PMID: 25969341. 
30) Lecky F, Benger J, Mason S, Cameron P, Walsh C; IFEM Quality Symposium Working Group. The International Federation for Emergency Medicine framework for quality and safety in the emergency department. Emerg Med J. 2014; 11(31): 926-9. doi: 10.1136/emermed-2013-203000. PMID: 23907367.

31) Alessandrini E, Varadarajan K, Alpern ER, Gorelick MH, Shaw K, Ruddy RM, Chamberlain JM; Pediatric Emergency Care Applied Research Network. Emergency department quality: an analysis of existing pediatric measures. Acad Emerg Med. 2011; 18(5): 519-26. doi: 10.1111/j.1553-2712.2011.01057.x. PMID: 21569170.

32) Moore L, Lavoie A, Bourgeois G, Lapointe J. Donabedian's structure-process-outcome quality of care model: Validation in an integrated trauma system. J Trauma Acute Care Surg. 2015; 78(6): 1168-75. doi: 10.1097/TA.0000000000000663. PMID: 26151519.

33) Gardner G, Gardner A, O'Connell J. Using the Donabedian framework to examine the quality and safety of nursing service innovation. J Clin Nurs. 2014; 23(1-2): 145-55. doi: 10.1111/jocn.12146. PMID: 23834585.

34) Jayadevappa R, Chhatre S. Patient centered care-a conceptual model and review of the state of the art. The Open Health Services and Policy J. 2011; 4(1): doi: 10.2174/1874924001104010015

35) Pedroto I, Amaro P, Romãozinho JM. Health systems organization for emergency care. J Best Practice \& Research Clinical Gastroenterology. 2013; 27(5): 819-27. doi: 10.1016/j.bpg.2013.08.014.

36) Carayon P, Wetterneck TB, Rivera-Rodriguez AJ, Hundt AS, Hoonakker P, Holden R, et al. Human factors systems approach to healthcare quality and patient safety. Appl Ergon. 2014; 45(1): 14-25. doi: 10.1016/j.apergo.2013.04.023. PMID: 23845724, PMCID: PMC3795965.

37) Tsiknakis M, Kouroubali A. Organizational factors affecting successful adoption of innovative eHealth services: A case study employing the FITT framework. Int J Med Inform. 2009; 78(1): 39-52. doi: 10.1016/j.ijmedinf.2008.07.001. PMID: 18723389.

38) Graff L, Stevens C, Spaite D, Foody J. Measuring and improving quality in emergency medicine. Acad Emerg Med. 2002: 9(11); 1091-107. doi: 10.1111/j.1553-2712.2002.tb01563.x. PMID: 12414457.

39) Salminen-Tuomaala M, Leikkola P, Paavilainen E. Emergency health care professionals' experiences of factors that influence care quality and safety. J Clinical Nursing Studies. 2015; 3(3): 60. doi: $10.5430 /$ cns.v3n3p60.

40) Hoot NR, Aronsky D. Review of emergency department crowding: Causes, effects, and solutions. Ann Emerg Med. 2008; 52(2): 127-36. doi: 10.1016/j.annemergmed.2008.03.014. PMID: 18433933.

41) Bahadori M, Ravangard R, Yaghoubi M, Alimohammadzadeh K. Assessing the service quality of Iran military hospitals: Joint Commission International standards and Analytic Hierarchy Process (AHP) technique. J Educ Health Promot. 2014; 3: 98. doi: 10.4103/2277-9531.139680. PMID: 25250364, PMCID: PMC4165109.

42) Taghva A, Azizi M, Rajabian MH, Khademi M, Omid A, Donyavi V, et al. Average Military Service Length and Soldiers' General Health. J Archives in Military Medicine. 2014; 2(4). doi: 10.5812/jamm.20604. 